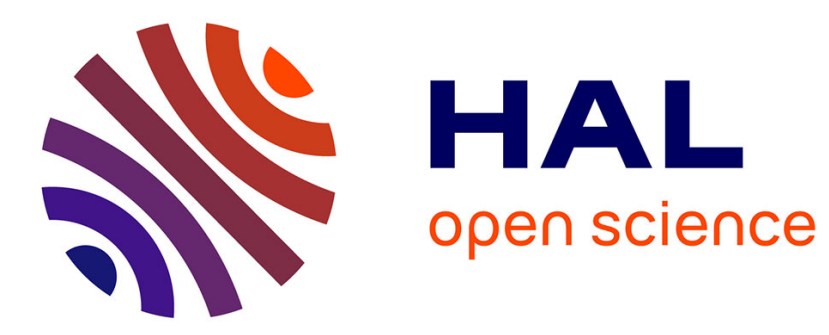

\title{
Phase boundaries of antiferromagnetic Cs2[FeCl5(H 2O)]
}

\author{
A. Paduan, F. Palacio, R.L. Carlin
}

\section{To cite this version:}

A. Paduan, F. Palacio, R.L. Carlin. Phase boundaries of antiferromagnetic Cs2[FeCl5(H 2O)]. Journal de Physique Lettres, 1978, 39 (16), pp.279-281. 10.1051/jphyslet:019780039016027900 . jpa00231497

\section{HAL Id: jpa-00231497 https://hal.science/jpa-00231497}

Submitted on 1 Jan 1978

HAL is a multi-disciplinary open access archive for the deposit and dissemination of scientific research documents, whether they are published or not. The documents may come from teaching and research institutions in France or abroad, or from public or private research centers.
L'archive ouverte pluridisciplinaire HAL, est destinée au dépôt et à la diffusion de documents scientifiques de niveau recherche, publiés ou non, émanant des établissements d'enseignement et de recherche français ou étrangers, des laboratoires publics ou privés. 


\title{
PHASE BOUNDARIES OF ANTIFERROMAGNETIC $\mathrm{Cs}_{2}\left[\mathrm{FeCl}_{5}\left(\mathrm{H}_{2} \mathrm{O}\right)\right]$
}

\author{
A. PADUAN FILHO $(*)$, F. PALACIO $\left({ }^{* *}\right)$ and R. L. CARLIN \\ Department of Chemistry, University of Illinois at Chicago Circle, Chicago, Illinois 60680, USA
}

( Reçu le 5 juin 1978, accepté le 29 juin 1978)

\begin{abstract}
Résumé. - La susceptibilité à champ nul de $\mathrm{Cs}_{2}\left[\mathrm{FeCl}_{5}\left(\mathrm{H}_{2} \mathrm{O}\right)\right]$ peut être exprimée par le développement en séries à haute température du modèle de Heisenberg à trois dimensions pour $S=5 / 2$, avec $J / k=-0,31 \mathrm{~K}$. Certaines portions des limites de phases magnétiques ont été mesurées, montrant que $H_{\mathrm{SF}}(0)=11,5 \mathrm{kOe}, H_{\mathrm{A}} / H_{\mathrm{E}}=1,2 \times 10^{-2}$, et que le point bicritique se trouve à environ $6,3 \mathrm{~K}$ et $14,7 \mathrm{kOe}$. Puisque $T_{\mathrm{c}}(0)=6,57 \mathrm{~K}$, un ordre de grandeur plus bas que pour $\mathrm{MnF}_{2}$ ou $\mathrm{RbMnF}_{3}$, c'est un nouvel exemple important d'antiferromagnétisme de Heisenberg à trois dimensions.
\end{abstract}

Abstract. - The zero-field susceptibility of $\mathrm{Cs}_{2}\left[\mathrm{FeCl}_{5}\left(\mathrm{H}_{2} \mathrm{O}\right)\right]$ may be fit by the 3-D Heisenberg, $S=5 / 2$, high-temperature series expansion, with $J / k=-0.31 \mathrm{~K}$. Portions of the magnetic phase boundaries have been measured, with the result that $H_{\mathrm{SF}}(0)=11.5 \mathrm{kOe}$, the bicritical point occurs at $\sim 6.3 \mathrm{~K}$ and $\sim 14.7 \mathrm{kOe}$, and $H_{\mathrm{A}} / H_{\mathrm{E}}=1.2 \times 10^{-2}$. Since $T_{\mathrm{c}}(0)=6.57 \mathrm{~K}$, which is an order of magnitude lower than that of either $\mathrm{MnF}_{2}$ or $\mathrm{RbMnF}_{3}$, this is an important new example of the 3-D Heisenberg antiferromagnet.

It was recently reported [1] that $\mathrm{Cs}_{2}\left[\mathrm{FeCl}_{5}\left(\mathrm{H}_{2} \mathrm{O}\right)\right]$ is antiferromagnetic with a critical temperature at zero-field, $T_{\mathrm{c}}(0)$, of $6.57 \pm 0.05 \mathrm{~K}$. Both zero-field susceptibility data, $\chi_{0}$, and specific heat results were presented for this $S=5 / 2$, orthorhombic material. Some difficulty was experienced in fitting the susceptibility data to the various magnetic model calculations that are available [2], but it was clear that the compound has fairly small magnetic anisotropy. Data are presented here which allow a quantitative measure of this anisotropy, and which also show that this new material is a good example of the three-dimensional Heisenberg model $[2,3]$.

A careful analysis of the $a$-axis data [1] has led to the value $\left(T_{\max }-T_{\mathrm{c}}\right) / T_{\max }=0.088$, where $T_{\max }$ is the temperature at which $\chi_{0}$ reaches its maximum value and $T_{\mathrm{c}}(0)$ is that temperature at which $\partial \chi_{0} / \partial T$ has its maximal value, that is, the critical temperature.

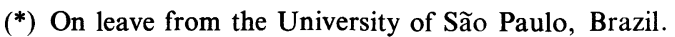

(**) On leave from the Departamento de Fisica Fundamental. University of Zaragoza, Spain.
The $a$-axis is the preferred axis of spin-alignment. This value of the above ratio is typical of that found with other three-dimensional Heisenberg antiferromagnets (3-D HA-F) such as $\mathrm{RbMnF}_{3}$ (which is more nearly isotropic) and agrees well with the theoretical expectation of 0.08 [4]. More importantly. we illustrate in figure 1 the fit to the susceptibility data [1] of the high-temperature series expansion for the susceptibility of the s.c., $S=5 / 2$ HA-F, as provided by de Jongh and Breed [4], the series being expanded in terms of $t=k T /|J| S(S+1)$. In order to observe the influence of the final term in the series for small values of the parameter $t$ and to find the minimum temperature down to which we might extend the calculation of the susceptibility, we have calculated it with all the terms available $(n=7)$ as well as with $n=6$ and 5 . Our results are essentially the same as those obtained in reference [4], hence we have extended our calculations down to $t=2.4$ as shown in figure 1 . The value of

$$
-J / k=0.310 \pm 0.005 \mathrm{~K},
$$




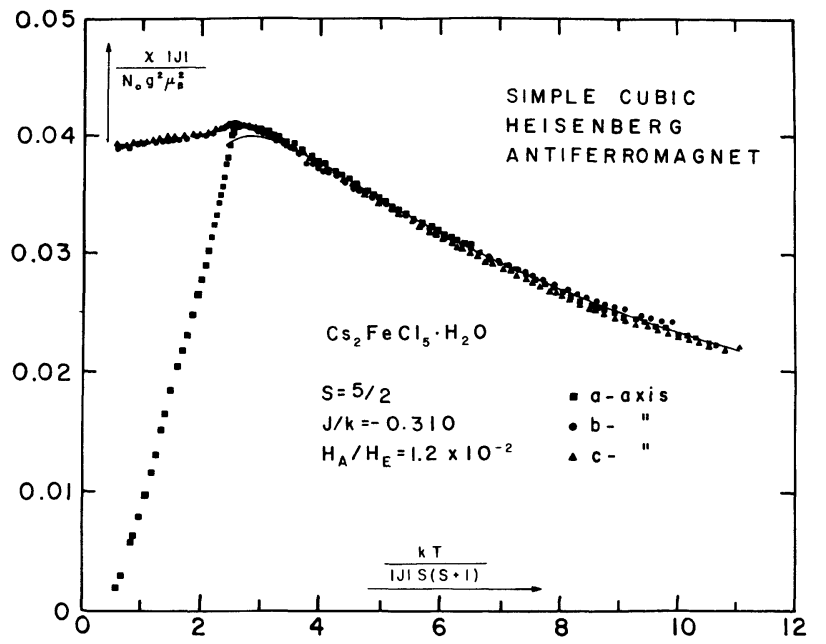

FIG. 1. - The points are the experimental data of O'Connor [1], and the solid curve is the calculated high temperature series expansion, as described in the text.

a value which may be compared (assuming $z=6$ ) with the values $0.29-0.33 \mathrm{~K}$ reported earlier [1]. and obtained by molecular field and spin-wave $(T=0)$ calculations. As may be seen from figure 1 there is good agreement between calculated and experimental points above $T \simeq 3.0$. Below this point the agreement is within $2 \%$.

No attempt was made to use extrapolation procedures for the calculated values of the susceptibility would not improve for $t<2.8$, as they would be lower than the calculated ones. A possible reason for this small discrepancy is that the system is orthorhombic rather than an ideal simple cubic one.

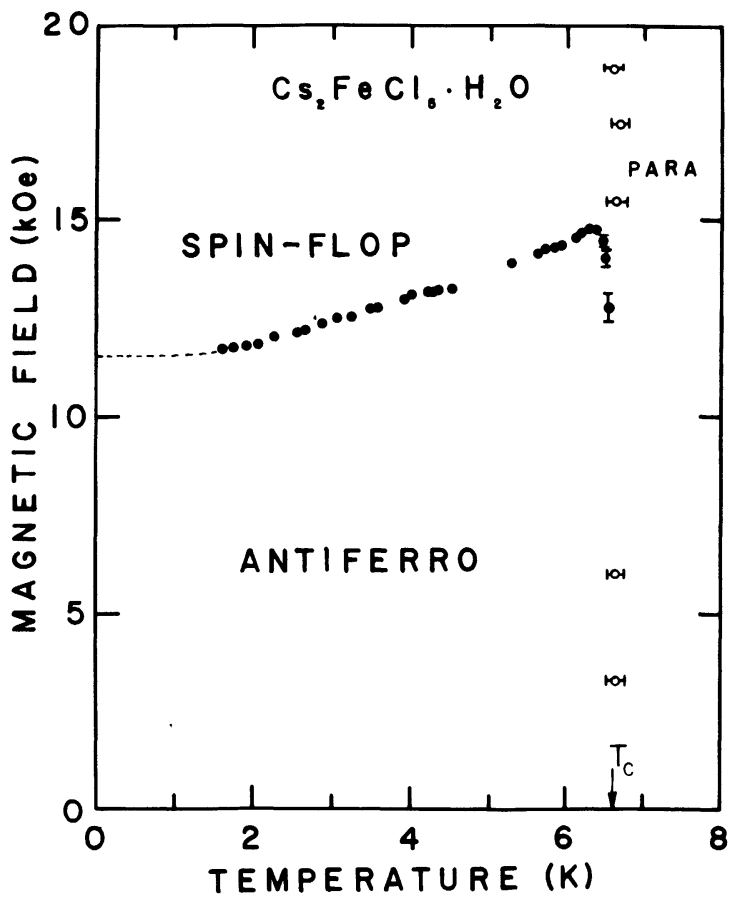

FIG. 2. - Magnetic phase boundaries of $\mathrm{Cs}_{2}\left[\mathrm{FeCl}_{5}\left(\mathrm{H}_{2} \mathrm{O}\right)\right]$. Filled points were obtained at constant $T$, and open points at constant $H$.
Portions of the magnetic phase diagram of $\mathrm{Cs}_{2}\left[\mathrm{FeCl}_{5}\left(\mathrm{H}_{2} \mathrm{O}\right)\right]$ are presented in figure 2. These results were obtained by measuring the differential magnetic susceptibility in an external magnetic field provided by a superconducting solenoid capable of producing $65 \mathrm{kOe}$. The magnetic susceptibility was measured between 1.6 and $7.0 \mathrm{~K}$ by an a.c. mutual inductance method using a bridge similar to that described by Maxwell [5]. The measuring field has been estimated to be 5 Oe, operating at a frequency of $155 \mathrm{~Hz}$. The temperature of the sample was controlled by a technique to be described elsewhere and measured by a carbon-glass resistor. The magnetic field dependence of the thermometer's resistance is less than $0.5 \%$ in the range of the field used. and may be neglected. The sample used was in parallelepiped shape elongated in the $a$ direction. The uncertainty in the alignment of the preferred direction $(a$-axis) with the magnetic field was estimated to be $3^{\circ}$.

Data were taken by sweeping the applied magnetic field while the temperature was kept constant or increasing the temperature at constant magnetic field. At constant temperature, the critical field was determined by a sharp peak in the susceptibility when the field crossed the phase boundary. In constant field, the phase transition was determined by the maximum value of $\mathrm{d} \chi / \mathrm{d} T$ for $H<H_{\mathrm{b}}$ or by a discontinuity in the susceptibility for $H>H_{\mathrm{b}}$. In the figure, typical error bars reflect an uncertainty in the data estimated from the value of the critical field or the localization of the transition temperature.

The bicritical point is found at $T_{\mathrm{b}}=6.3 \pm 0.2 \mathrm{~K}$ and $H_{\mathrm{b}}=14.7 \pm 0.1$ kOe. Taking the spin-flop field extrapolated to zero temperature as $H_{\mathrm{SF}}(0)=11.5 \mathrm{kOe}$ and $\chi_{\perp}(0)=0.19 \mathrm{emu} / \mathrm{mole}$ [1] we estimate the anisotropy field $H_{\mathrm{A}}=0.88 \mathrm{kOe}$ and the exchange field $H_{\mathrm{E}}=75.9 \mathrm{kOe}$. The ratio $\alpha=H_{\mathrm{A}} / H_{\mathrm{E}}=1.2 \times 10^{-2}$.

The AF-P boundary is quite vertical $\left(T_{\mathrm{b}} / T_{\mathrm{c}}(0)=0.96\right)$ as has been observed in such other low-anisotropy antiferromagnets as $\mathrm{CuCl}_{2} .2 \mathrm{H}_{2} \mathrm{O}$ [6] and $\mathrm{MnF}_{2}$ [7]. The main source of anisotropy in this material probably is the particular crystal structure. which is under detailed investigation [8]. Single-ion anisotropy in this type of compound appears to be small $[1,9]$.

We conclude that $\mathrm{Cs}_{2}\left[\mathrm{FeCl}_{5}\left(\mathrm{H}_{2} \mathrm{O}\right)\right]$ is about as good an example of the 3-D HA-F as is the isoelectronic $\mathrm{MnF}_{2}$, and comparable in anisotropy to the $S=1 / 2, \mathrm{CuCl}_{2} .2 \mathrm{H}_{2} \mathrm{O}$. What is interesting about this result is that $T_{\mathrm{c}}\left(\mathrm{MnF}_{2}\right)$ is about an order of magnitude higher than that of the compound reported here, while $T_{c}$ of $\mathrm{RbMnF}_{3}$, the least-anisotropic 3-D HA-F, is even higher, $83 \mathrm{~K}$ [4]. Thus, a variety of experiments can now be carried out on an $S=5 / 2$. 3-D HA-F more conveniently than in the past; one such example is the behaviour of the magnetic specific heat, for the lattice contribution in 
$\mathrm{Cs}_{2}\left[\mathrm{FeCl}_{5}\left(\mathrm{H}_{2} \mathrm{O}\right)\right]$ at $T_{\mathrm{c}}$ is a small fraction of the total. Nuclear resonance and Mössbauer experiments also are particularly attractive. These and other experiments on $\mathrm{Cs}_{2}\left[\mathrm{FeCl}_{5}\left(\mathrm{H}_{2} \mathrm{O}\right)\right]$ and its congeners are now in progress.

This research was supported by the National
Science Foundation under Grant No. DMR 7618963. A. P. F. is grateful for support given by the Fundacao de Amparo a Pesquisa do Estado de São Paulo, and F. P. is grateful for a grant from the Comite Conjunto Hispano Norteamericano Para Asuntos Educativos y Culturales.

\section{References}

[1] Carlin, R. L., Bhatia, S. N. and O'Connor, C. J., J. Amer. Chem. Soc. 99 (1977) 7728 ;

O'Connor, C. J., Thesis, University of Illinois at Chicago Circle, 1976 (unpublished).

[2] De Jongh, L. J. and Miedema, A. R., Adv. Phys. 23 (1974) 1.

[3] Carlin, R. L. and Van Duyneveldt, A. J., Magnetic Properties of Transition Metal Compounds (Springer-Verlag, New York) 1977.

[4] De Jongh, L. J. and Breed, D. J., Solid State Commun. 15 (1974) 1061
[5] MaXwell, E., Rev. Sci. Instrum. 36 (1965) 553.

[6] Butterworth, G. J. and Zidell, V. S., J. Appl. Phys. 40 (1969) 1033.

[7] Shapira, Y. and Becerra, C. C., Phys. Lett. A 57 (1976) 483 and A 58 (1976) 493.

[8] O'ConNor, C. J. and SinN, E., to be published.

[9] McElearney, J. N. and Merchant, S., Inorg. Chem. 17 (1978) 1207. 